Article

\title{
Bio-Phototransistors with Immobilized Photosynthetic Proteins
}

\author{
Arash Takshi ${ }^{1, *(\mathbb{C})}$, Houman Yaghoubi ${ }^{2}$, Daniel Jun ${ }^{3}$ and J. Thomas Beatty ${ }^{3}$ \\ 1 Department of Electrical Engineering, University of South Florida (USF), Tampa, FL 33620, USA \\ 2 Quidel Corporation Headquarters, 9975 Summers Ridge Rd, San Diego, CA 92121, USA; \\ yaghoubi.houman@gmail.com \\ 3 Department of Microbiology and Immunology, University of British Columbia (UBC), \\ Vancouver, BC V6T 1Z3, Canada; djun@live.ca (D.J.); j.beatty@ubc.ca (J.T.B.) \\ * Correspondence: atakshi@usf.edu; Tel.: +1-813-421-3037
}

Received: 26 September 2020; Accepted: 15 October 2020; Published: 18 October 2020

check for updates

\begin{abstract}
The efficient mechanism of light capture by photosynthetic proteins allows for energy transfer and conversion to electrochemical energy at very low light intensities. In this work, reaction center (RC) proteins, or a core complex consisting of the RC encircled by light harvesting (LH1) proteins (RC-LH1) from photosynthetic bacteria, were immobilized on an insulating layer of an ion-sensitive field-effect transistor (ISFET) to build bio-photodetectors. The orientation of the RC proteins was controlled via application of a hybrid linker made of 10-carboxydecylphosphonic acid and cytochrome $c$ that anchored the RCs to their electron donor side. Bio-phototransistors consisting of either the core RC or the RC-LH1 core complex were tested under white and monochromic light. The difference between the dark and light currents at different wavelengths are well-matched with the absorption spectrum of the photosynthetic proteins. The results show potential for the use of photosynthetic proteins in photodetectors.
\end{abstract}

Keywords: bio-phototransistor; reaction center; rhodobacter sphaeroides

\section{Introduction}

The mechanism of harvesting photons in the cells of photosynthetic organisms enables them to function effectively, even at low light intensities [1,2]. In addition, the quantum efficiency in generating separated electron-hole pairs due to absorbed photons inside the photosynthetic proteins is almost $100 \%$ [2]. Due to these unique characteristics, the application of photosynthetic proteins and cells has attracted growing interest for the fabrication of solar cells [3,4]. While the low overall efficiency and the limited lifetime of biomaterials are serious challenges for efficient energy production, the elegant mechanism of light absorption and charge separation in photosynthetic proteins is inspiring for the fabrication of ultrasensitive photodetectors. In this study, we have used the reaction center (RC) and the core complex of the RCs, surrounded by a light-harvesting unit (RC-LH1) from a photosynthetic bacterium, Rhodobacter ( $R$ b.) sphaeroides, to make photo-sensors. It should be noted that the application of photosynthetic proteins in sensing devices is new and challenging. The results presented in this work are a proof of concept for the feasibility of employing RCs and RC-LH1s as the photoactive elements in photodetectors. Yet, due to some limitations, such as the limited absorption spectrum in the proteins $(\sim 750 \mathrm{~nm}<\lambda<\sim 950 \mathrm{~nm})$, the performance of a bio-photodetector is not comparable to state-of-art technologies using no biomaterials.

Within a photosynthetic bacterium, for every RC, there are light-harvesting (LH) proteins that contain pigments which absorb photons like antennae. Through a Förster resonance mechanism, the energy of the photons is funneled to the closest light-harvesting protein layer (LH1) encircling the 
$R C$, through which the energy is delivered to the RC with high efficiency. As shown in Figure 1a, the RC protein is surrounded by the LH1 layer, forming the RC-LH1 core complex. The charge separation process occurs inside the $\mathrm{RC}$ proteins. Figure $1 \mathrm{~b}$ is a schematic of the $\mathrm{RC}$ showing the structure of the protein, consisting of three protein subunits called $\mathrm{L}, \mathrm{M}$ and $\mathrm{H}$, with embedded cofactors that are the main elements in converting photons to electric charges. A photon absorbed by an RC generates an excited state in a pair of bacteriochlorophylls (BChls), called the special pair (P). The excited electron is then transferred to an accessory $\mathrm{BChl}\left(\mathrm{B}_{\mathrm{A}}\right)$, then to a bacteriopheophytin (BPhe) and subsequently to a primary $\left(\mathrm{Q}_{\mathrm{A}}\right)$ and secondary $\left(\mathrm{Q}_{\mathrm{B}}\right)$ quinone [5]. As shown in Figure $1 \mathrm{c}$, the electron path is in favor of the electron moving from $P$ to $Q_{B}$ due to the lower energy level at $Q_{B}$. This process leaves a hole (positive charge) at $\mathrm{P}$, with an electron at $\mathrm{Q}_{\mathrm{B}}$ forming a dipole inside the RC. The multi-step electron transfer facilitates the charge separation and lowers the probability of charge recombination inside the $\mathrm{RC}$. Due to this process, the photo-generated dipole is very stable, with a recombination time of $\sim 1 \mathrm{~s}$ [6].

(a)

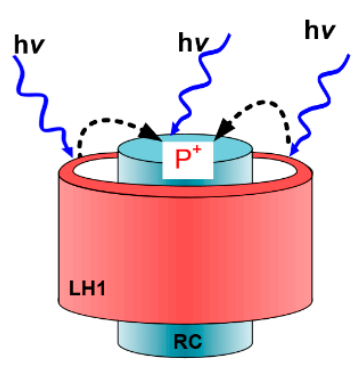

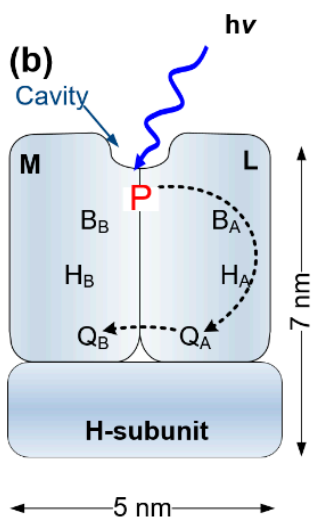

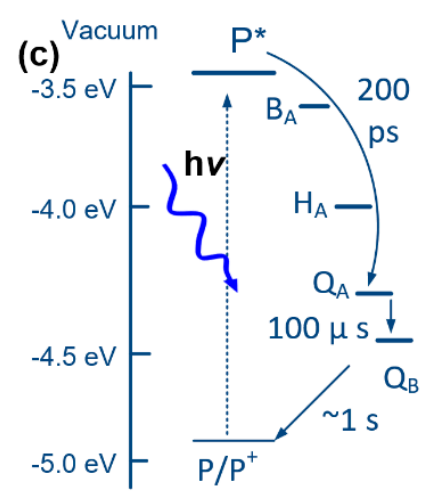

Figure 1. Schematics of (a) the reaction center light-harvesting (RC-LH1) complex and (b) the RC protein. (c) The energy levels inside the RC. (b) M, L and $\mathrm{H}$ are the three subunits in the RC. The special pair $(\mathrm{P})$, accessory bacteriochlorophyll $\left(\mathrm{B}_{\mathrm{A}}\right), \mathrm{B}_{\mathrm{B}}, \mathrm{H}_{\mathrm{A}}, \mathrm{H}_{\mathrm{B}}$, primary quinone $\left(\mathrm{Q}_{\mathrm{A}}\right)$ and secondary quinone $\left(Q_{B}\right)$ are different parts of the cofactors being embedded inside the $R C$. The cavity at the $P$ side is where cytochrome c (cyt $c$ ) attaches to the protein. The electron path inside the cofactors are shown with the dashed arrows.

In the native organism, the negative charge at $\mathrm{Q}_{\mathrm{B}}$ is neutralized by a proton acquired from the cell cytoplasm forming hydroquinone. The positive charge is also transferred from $\mathrm{P}^{+}$to a cytochrome $c$ (cyt $c$ ) protein, which acts as a charge mediator [6]. The interaction between cyt $c$ and the RC occurs through a docking mechanism, in which cyt $c$ binds to the RC residues in a depression on the $\mathrm{P}$ side of the protein (Figure 1b) [7]. As we have shown previously (and also applied in this study), the interaction between an RC and a cyt $c$ is sufficiently stable for immobilization of properly oriented RCs [8-10].

To employ the unique mechanism of photon absorption and charge separation in RCs for light detection, it is required to keep them in an electrochemical cell. In a conventional approach, the proteins are immobilized on the surface of a conductive electrode to be used in the electrochemical cell $[5,9,11-13]$. The photo-generated electrons or holes are transferred to the conductive electrode to produce a photocurrent that is proportional to the intensity of the absorbed light. In this design, the orientation of the immobilized RCs is critical for collecting either the negative or positive charges. Various immobilization methods using linker molecules and specific tags on the protein have been demonstrated before [4]. Nevertheless, those approaches rely on the charge transfer from the protein to the electrode, which can be limited due to the relatively large distance between either the $\mathrm{P}^{+}$or $\mathrm{Q}_{\mathrm{B}}{ }^{-}$ on the RC and the electrode surface. The novel approach in this work is to employ the proteins in an electrochemical transistor design, where the generated dipole can change the transistor's drain current without any need for the charge transfer from the protein. With this design, RCs can act 
as photosensitive elements in liquid media that are potentially suitable for designing miniaturized spectrometers operating in water and other liquids, such as blood.

To eliminate charge transfer limitation, a common approach in biosensors is to use an electrochemical transistor with the immobilized biomaterials on top of their insulating layer [14]. The mechanism of operation in an electrochemical transistor is very similar to a metal-oxide field effect transistor (MOSFET) that is well explained in [15]. The insulating layer (the $\mathrm{SiO}_{2}+\mathrm{Si}_{3} \mathrm{~N}_{4}$ layer in Figure 2) between the electrolyte and the semiconductor forms a capacitor. The biomaterials attached to the insulating layer at the electrolyte side impact the charge distribution on the semiconductor layer between the drain and source contacts. Hence, the effect of the biomaterials can be measured via monitoring the drain current without any need for the charge transfer from the biomaterial to any of the electrochemical electrodes. Different forms of bio-transistors (also known as Bio-FETs) have been reported for the detection of proteins, DNAs, viruses and cells [16]. In almost all of these devices, the transistor detects successful coupling between the target biomaterial in the electrolyte and the engineered immobilized bio-receptor [14]. However, in this work, we have employed the photo-generated dipoles on already immobilized proteins on top of the gate insulator. Two Bio-FETs (one with the immobilized RCs and the other one with a layer of RC-LH1 as a photoactive layer) were studied as photodetectors by monitoring their response to light at various wavelengths. Figure 2 shows the schematic of the fabricated devices.

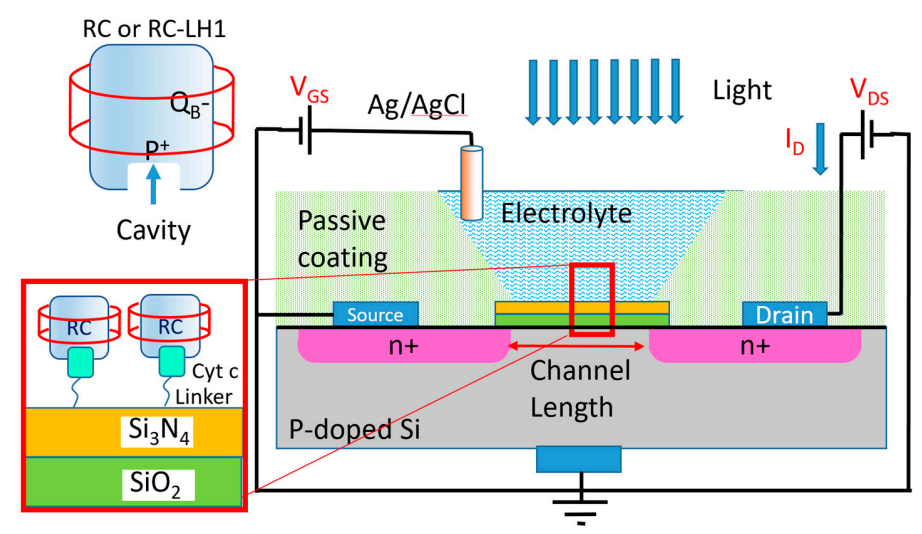

Figure 2. (Right) A schematic of the photodetector. The devices were characterized in the dark and light by measuring $I_{D}$ while applying voltages to $V_{D S}$ and $V_{G S}$. (Top left) Simplified schematic of the RC or RC-LH1 proteins. (Bottom left) The structure of the immobilized RC or RC-LH1 proteins, using a hybrid linker of immobilized cyt $c$ on the surface of $\mathrm{Si}_{3} \mathrm{~N}_{4}$, as shown in the zoomed-in box. The naturally occurring interactions between the cyt $c$ and the cavity on the RC were used to control the orientation of the RCs.

\section{Materials and Methods}

Silicon-based electrochemical transistors with $98 \mathrm{~nm}$ thick $\mathrm{SiO}_{2}$ and $100 \mathrm{~nm}$ thick $\mathrm{Si}_{3} \mathrm{~N}_{4}$ gate insulators were purchased from Microsense. The gate area of the transistor was approximately $\mathrm{W}=2 \mathrm{~mm} \times \mathrm{L}=1 \mathrm{~mm}$. The transistors were immersed into disposable cuvettes $(1 \mathrm{~cm} \times 1 \mathrm{~cm} \times 4 \mathrm{~cm})$ filled with a solution of $0.75 \mathrm{mM}$ of methyl viologen (MV) in a $0.1 \mathrm{M}$ Tris- $\mathrm{HCl}$ buffer (pH 8.0) as the electrolyte. An Ag/AgCl reference electrode was used as the gate contact (Figure 2). The transistors were tested before and after protein immobilization under dark and light conditions.

Wild-type RCs from $R b$. sphaeroides were isolated using a modified version of the method of Goldsmith and Boxer $[5,17,18]$. Briefly, cells were centrifuged at $9000 \mathrm{~g}$ and suspended in $10 \mathrm{mM}$ Tris ( $\mathrm{pH}$ 8), $150 \mathrm{mM} \mathrm{NaCl}$ and $2 \mathrm{mM} \mathrm{MgCl}_{2}$ [5]. The cells were broken by two passages through a French press. Broken cells were centrifuged at $9000 \mathrm{~g}$ to pellet unbroken cells, and the supernatant was centrifuged overnight at 30,000 rpm in a Beckman Coulter Type 70 Ti rotor to pellet the membranes. Membranes were suspended in $10 \mathrm{mM}$ Tris (pH 8) and $150 \mathrm{mM} \mathrm{NaCl}$ and solubilized with $1.5 \%$ $N, N$ dimethyldodecylamine $\mathrm{N}$-oxide (LDAO). Solubilized membranes were ultra-centrifuged at 
541,000 $g$, and 6-His-tagged RCs were purified from the supernatant using affinity chromatography [19]. The concentration of RCs after purification was determined by their absorption at $804 \mathrm{~nm}$, as described by Goldsmith and Boxer [18].

The production and purification of the RC-LH1 in Rb. sphaeroides were similar to the description by Abresch et al. [20]. All protein solutions utilized a buffer of $10 \mathrm{mM}$ Tris- $\mathrm{HCl}, \mathrm{pH} 8$, and $25 \mathrm{mM} \mathrm{NaCl}$. Membranes were solubilized with $0.5 \%$ sodium cholate combined with $4 \% n$-octyl- $\beta$-D-glucopyranoside (BOG), and the 6-His-tagged proteins were bound to a $\mathrm{Ni}^{2+} / \mathrm{NTA}$ column. The detergent was then changed to a combination of $0.2 \%$ sodium cholate and $0.06 \% n$-dodecyl- $\beta$-D-maltopyranoside (DDM) in all of the following steps. The column was washed with 10 column volumes of buffer solution containing $5 \mathrm{mM}$ imidazole, and the protein was eluted from the column by raising the concentration of the imidazole to $150 \mathrm{mM}$. The column eluate was layered onto a sucrose gradient $(15 \%$ to $35 \%)$ and centrifuged in a Beckman SW41 swinging bucket rotor at $4{ }^{\circ} \mathrm{C}$ for $44 \mathrm{~h}$ at $30,000 \mathrm{rpm}$. The bottom of the two bands was collected, and the sucrose was removed by dialysis.

Buffer solutions with RC and RC-LH1 concentrations of $5 \mu \mathrm{M}$ were prepared and used for the fabrication of the Bio-FETs. A hybrid linker structure consisting of a self-assembled monolayer (SAM) of 10-carboxydecylphosphonic acid and immobilized cyt $c$ was used to immobilize the photosynthetic proteins on the $\mathrm{Si}_{3} \mathrm{~N}_{4}$ layer of the transistor from the $\mathrm{P}^{+}$side of the proteins. The immobilization was done by first forming the SAM by inserting the transistor into an ethanolic solution of $10 \mathrm{mM}$ 10-carboxydecylphosphonic acid (Dojindo) for $4 \mathrm{~h}$ at room temperature. After this step, the transistor was rinsed in ethanol, followed by a deionized water rinse to remove the loosely bound SAM. Equine cyt $c$ (purchased from Sigma and used without purification) was deposited on the SAM by inserting the Bio-FET into a $0.8 \mathrm{mM}$ solution of cyt $c$ in a \# mM Tris buffer ( $\mathrm{pH} \mathrm{8.0)}$ for $24 \mathrm{~h}$ at room temperature. RC and RC-LH1 incubation were carried out by drop-casting $20 \mu \mathrm{L}$ of the protein solutions $(5 \mu \mathrm{M})$ on top of the active area of the transistor and keeping it at $4{ }^{\circ} \mathrm{C}$ for $24 \mathrm{~h}$. The devices were rinsed before being used in the electrochemical cell.

The electrochemical cells were tested using a custom-made setup, including a dark box with a white light-emitting diode (LED) and a multi-wavelength LED (MTMD6788594SMT6 from Marktech Optoelectronics) as the light sources inside the box. Each LED was biased with a $20 \mathrm{~mA}$ current to get white light emission and single wavelength emissions at 670, 770, 810, 850 and $950 \mathrm{~nm}$. From the datasheet of the LED, the intensity of the monochromatic light was estimated to be $\sim 3 \mu \mathrm{W} / \mathrm{cm}^{2}$ at the transistor surface. The transistor was characterized using a 2602A Keithley instrument. The Keithley instrument and the pulse current source for the LEDs were controlled through LabTracer 2.0 software.

\section{Results}

First, an electrochemical transistor without any coating on the gate insulator was tested under dark conditions. According to the datasheet of the device, the transistors had a threshold voltage of $V_{t h}=\sim 2.4 \mathrm{~V}$. To obtain the output characteristics of the devices, a constant voltage was applied between the gate (i.e., the $\mathrm{Ag} / \mathrm{AgCl}$ electrode) and the source while the voltage of the drain was scanned from $0.0 \mathrm{~V}$ to $1.0 \mathrm{~V}$, and the drain current was measured. Figure 3 a shows the response of the transistor at three different bias voltages of $V_{G S}=2.5 \mathrm{~V}, 2.75 \mathrm{~V}$ and $3.0 \mathrm{~V}$. The device clearly showed the enhancement mode operation with the distinct triode and saturation regimes. The saturation current reached $33.4 \mu \mathrm{A}$ at $V_{D S}=1.0 \mathrm{~V}$ when $\mathrm{V}_{\mathrm{GS}}$ was $3.0 \mathrm{~V}$. The same device was tested after the formation of the SAM and immobilization of the cyt $c$ on the gate insulating layer. Figure $3 \mathrm{~b}$ shows the output characteristics of the device after forming the hybrid linker on top of the gate insulator. In this case, the drain current was increased to $70.5 \mu \mathrm{A}$. RC proteins without the LH1 were immobilized on the hybrid linker using the natural docking mechanism between the RC and the cyt $c$. The device with the immobilized RC was then tested in the dark (Figure 3c). In this case, the drain current dropped to $66.5 \mu \mathrm{A}$ at $V_{D S}=1.0 \mathrm{~V}$ and $V_{G S}=3.0 \mathrm{~V}$. The same functionalization process to deposit the hybrid linker on the $\mathrm{Si}_{3} \mathrm{~N}_{4}$ layer was performed on a different transistor. Then, the RC-LH1 was immobilized on 
the second transistor. Figure $3 \mathrm{~d}$ shows the output characteristics of the device under dark conditions. A drain current of $59.0 \mu \mathrm{A}$ was achieved from the transistor.
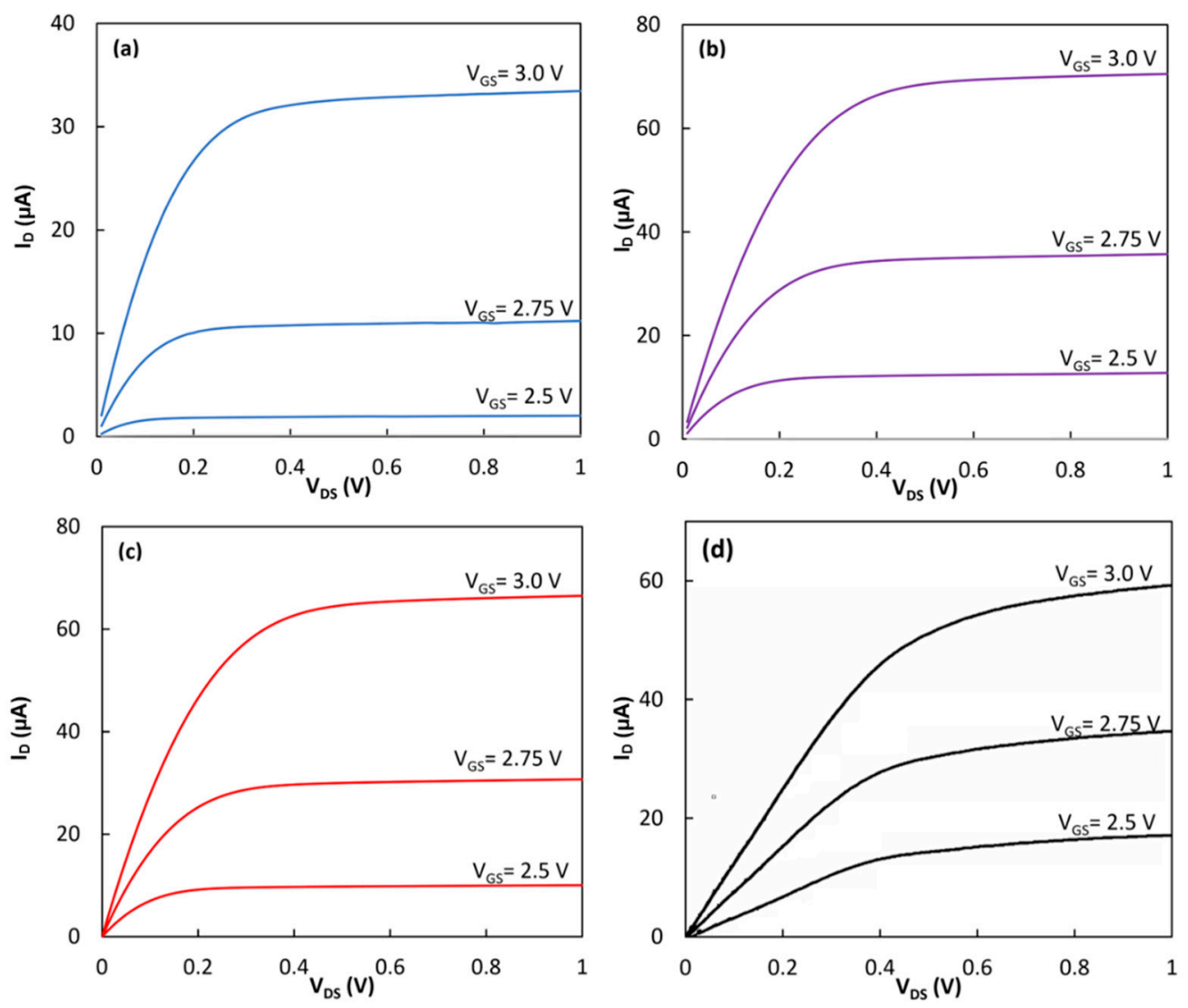

Figure 3. The output characteristics in the dark of (a) the bare electrochemical transistor, (b) the transistor with the hybrid linker of the self-assembled monolayer (SAM) and the cyt $c$, (c) the photodetector with the immobilized RCs and (d) the photodetector with the immobilized RC-LH1 proteins.

Both devices with the immobilized proteins were tested under white and monochromic light from LEDs. Figure 4a shows that the output characteristics of the device with the RC-LH1 proteins had an increase in the drain current from its dark value of $59.0 \mu \mathrm{A}$ to $62.0 \mu \mathrm{A}$ under white light when the gate was biased at $3.0 \mathrm{~V}$ and the $V_{D S}$ was $1.0 \mathrm{~V}$. The output characteristics of the first device in the dark and upon illumination with white and monochromic light are shown in Figure $4 \mathrm{~b}$. While the current increased from $66.5 \mu \mathrm{A}$ in the dark to $72.2 \mu \mathrm{A}$ upon white light illumination, the value of the current was different under monochromic lights.

The drain current difference, $\Delta I_{D}$, between light and dark at $V_{D S}=1.0 \mathrm{~V}$ and $V_{G S}=3.0 \mathrm{~V}$ for each wavelength has been calculated for both transistors. As shown in Figure $5, \Delta I_{D}$ has a relatively consistent correlation with the absorption spectrum in the RC and RC-LH1 proteins. 

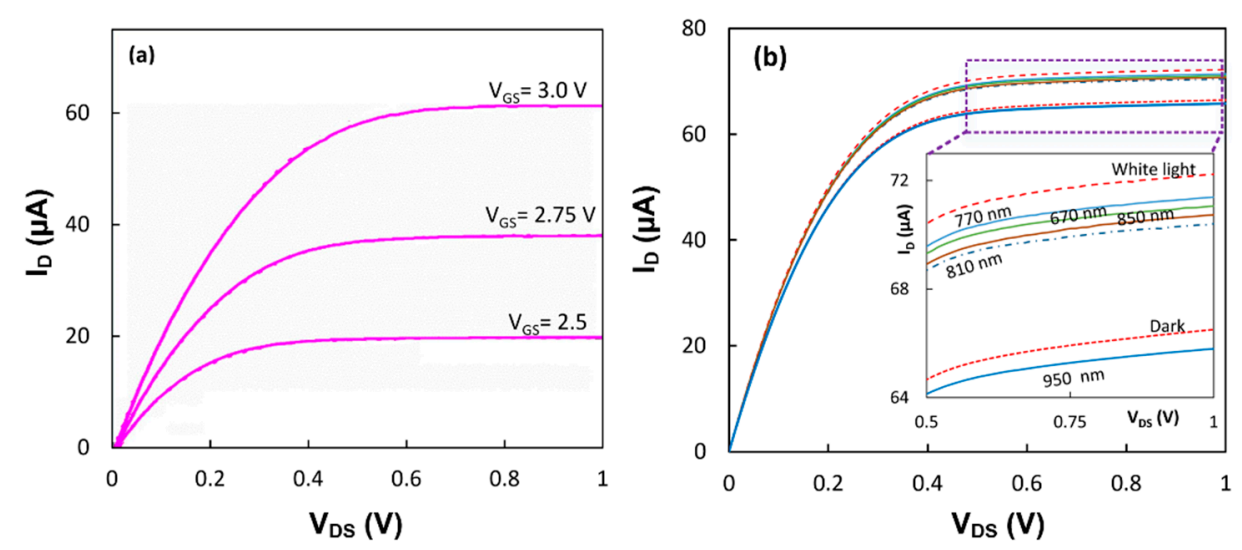

Figure 4. (a) Output characteristics of the device with immobilized RC-LH1 proteins under white light illumination with the intensity of $\sim 3 \mu \mathrm{W} / \mathrm{cm}^{2}$. (b) Output characteristics of the device with immobilized RCs in the dark and illuminated with white and monochromic lights. The response to the bias of only $V_{G S}=3.0 \mathrm{~V}$ is shown. (inset) Zoomed-in image of the plot showing the saturation currents.

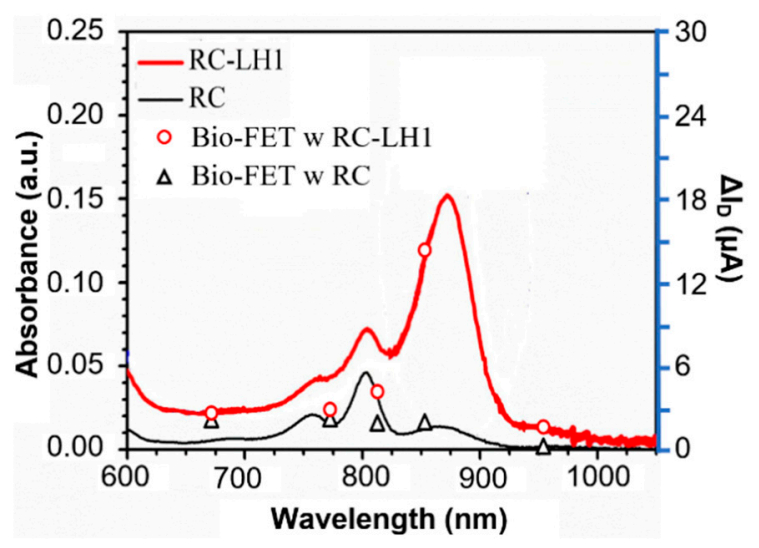

Figure 5. The change between the saturation current at $V_{D S}=1.0 \mathrm{~V}$ under illumination and in the dark from both transistors matches with the absorption spectrum of the RC and RC-LH1 proteins in the buffer solution.

\section{Discussion}

The drain saturation current, $I_{D}$, in an enhancement transistor is expressed by [15]

$$
I_{D}=\frac{\mu \cdot C_{G}}{2} \frac{W}{L}\left(V_{G S}-V_{t h}\right)^{2},
$$

where $\mu$ is the mobility of the carrier in the channel of the transistor, $W / L$ is the channel's width-to-length ratio and $C_{G}$ is the gate capacitance. Since $\mu, \mathrm{W}$ and $\mathrm{L}$ do not change after the formation of the linker and immobilization of the proteins, the variation in the drain current can either be due to the change in the gate capacitance or the threshold voltage. To understand the effect of different layers, trans-characteristics $\left(I_{D}-V_{G S}\right)$ of the first transistor at $V_{D S}=1.0 \mathrm{~V}$ before and after the deposition of each layer have been studied and plotted in Figure 6a. Since there is a quadratic function between the current and voltage, the square root of the drain current versus $V_{G S}$ is plotted in Figure $6 \mathrm{~b}$. The results clearly show that the SAM layer of the linker molecule had a negligible impact on the threshold voltage and $C_{G}$. However, the immobilized cyt $c$ shifted the threshold voltage from $V_{\text {th }}=2.42 \mathrm{~V}$ to $2.15 \mathrm{~V}$. Since the slope had not changed, the shift in the threshold voltage implies that the positive charge, most likely from the $\mathrm{Fe}^{2+}$ inside the cyt $c$, affected the density of the electrons in the silicon channel [15]. This can be explained via the flat-band voltage in an FET device, which is a function of fixed charges at the gate insulator interface [15]. RC immobilization also showed a shift in the threshold voltage 
without changing the gate capacitance. The increase in the threshold voltage to $V_{\text {th }}=2.20 \mathrm{~V}$ indicates that the center of charge in the coupled cyt $c$ with the RC shifted away from the gate insulator. However, the larger drain current under illumination than in the dark suggests that the photo-generated dipoles inside RCs reduce the threshold voltage in the transistor p15]. While the results show the compatibility between the drain current and the absorption spectrum of the proteins, it is expected that shorter linkers on the gate insulator would enhance the effect of the dipoles on the drain current and improve the photosensitivity of the devices.
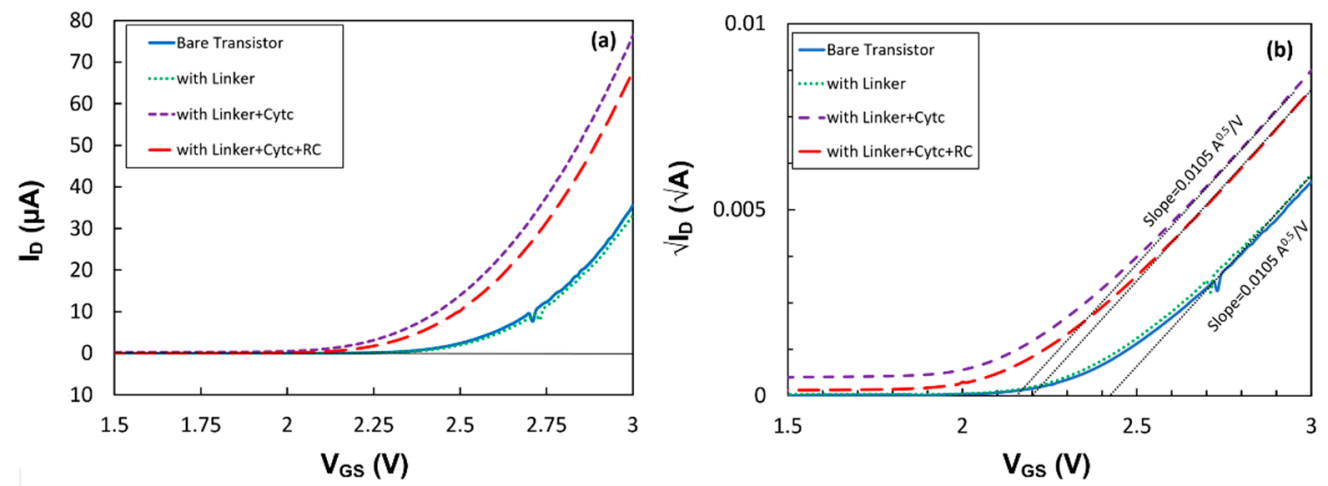

Figure 6. (a) $I_{D}$ vs. $V_{G S}$ and (b) $\sqrt{ } I_{D}$ vs. $V_{G S}$ for a transistor at four different stages of RC immobilization: bare transistor, with the SAM, with the SAM and cyt $c$, and with the SAM, cyt $c$ and immobilized RCs. The measurements were conducted at $V_{D S}=1.0 \mathrm{~V}$.

\section{Conclusions}

The RC and RC-LH1 complex proteins from $R b$. sphaeroides were immobilized on the gate insulator of two electrochemical transistors using a hybrid linker of a SAM and immobilized cyt $c$. The output characteristics of the devices were measured under dark and illuminated conditions. The variation in the drain current from each device matched the absorption spectrum of the proteins. Due to the absorption spectrum of LH1, the transistor equipped with the light-harvesting proteins was more sensitive to the infrared light, particularly around $\lambda=850 \mathrm{~nm}$. The results are promising for the fabrication of photodetectors with a higher sensitivity by modifying the linker structure to bring the proteins closer to the surface of the transistor.

Author Contributions: A.T. is the PI of the project at USF who designed and performed the experiments. D.J. and J.T.B. grew the photosynthetic bacteria and prepared the RC complexes at UBC. A.T. and H.Y. analyzed the data. All the authors contributed to writing the paper. All authors have read and agreed to the published version of the manuscript.

Funding: This work was supported by an NSF 1,400,017 (USA) grant to A.T., and the research of J.T.B. was supported by a grant (RGPIN 2018-03898) from the Canadian Natural Sciences and Engineering Research Council (NSERC).

Acknowledgments: In this section you can acknowledge any support given which is not covered by the author contribution or funding sections. This may include administrative and technical support, or donations in kind (e.g., materials used for experiments).

Conflicts of Interest: The authors declare no conflict of interest.

\section{References}

1. Beatty, J.T.; Overmann, J.; Lince, M.T.; Manske, A.K.; Lang, A.S.; Blankenship, R.E.; Van Dover, C.L.; Martinson, T.A.; Plumley, F.G. An obligately photosynthetic bacterial anaerobe from a deep-sea hydrothermal vent. Proc. Natl. Acad. Sci. USA 2005, 102, 9306-9310. [CrossRef] [PubMed]

2. Blankenship, R.E. Molecular Mechanisms of Photosynthesis; Blackwell Science: Maiden, MA, USA, 2002.

3. Kim, Y.; Shin, S.A.; Lee, J.; Yang, K.D.; Nam, K.T. Hybrid system of semiconductor and photosynthetic protein. Nanotechnology 2014, 25, 342001. [CrossRef] [PubMed] 
4. Yaghoubi, H.; Li, Z.; Jun, D.; Saer, R.; Slota, J.E.; Beerbom, M.; Schlaf, R.; Madden, J.D.; Beatty, J.T.; Takshi, A. The Role of Gold-Adsorbed Photosynthetic Reaction Centers and Redox Mediators in the Charge Transfer and Photocurrent Generation in a Bio-Photoelectrochemical Cell. J. Phys. Chem. C 2012, 116, 24868-24877. [CrossRef]

5. Feher, G.; Allen, J.P.; Okamura, M.Y.; Rees, D.C. Structure and function of bacterial photosynthetic reaction centres. Nature 1989, 339, 111-116. [CrossRef]

6. Axelrod, H.L.; Abresch, E.C.; Okamura, M.Y.; Yeh, A.P.; Rees, D.C.; Feher, G. X-ray Structure Determination of the Cytochrome c2: Reaction Center Electron Transfer Complex from Rhodobacter sphaeroides. J. Mol. Biol. 2002, 319, 501-515. [CrossRef]

7. Lebedev, N.; Trammell, S.A.; Spano, A.; Lukashev, E.; Griva, I.; Schnur, J. Conductive Wiring of Immobilized Photosynthetic Reaction Center to Electrode by Cytochrome c. J. Am. Chem. Soc. 2006, 128, 12044-12045. [CrossRef] [PubMed]

8. Yaghoubi, H.; Li, Z.; Jun, D.; Lafalce, E.; Jiang, X.; Schlaf, R.; Beatty, J.T.; Takshi, A. Hybrid Wiring of the Rhodobacter sphaeroides Reaction Center for Applications in Bio-photoelectrochemical Solar Cells. J. Phys. Chem. C 2014, 118, 23509-23518. [CrossRef]

9. Takshi, A.; Yaghoubi, H.; Wang, J.; Jun, D.; Beatty, J.T. Electrochemical field-effect transistor utilization to study the coupling success rate of photosynthetic protein complexes to cytochrome c. Biosensors 2017, 7, 16. [CrossRef] [PubMed]

10. Takshi, A.; Madden, J.D.; Beatty, J.T. Diffusion model for charge transfer from a photosynthetic reaction center to an electrode in a photovoltaic device. Electrochim. Acta 2009, 54, 3806-3811. [CrossRef]

11. Yaghoubi, H.; Jun, D.; Beatty, J.T.; Takshi, A. Photosynthetic Reaction Center Immobilization Through Carboxylic Acid Terminated $\backslash$ Cytochrome C Linker for Application in Photoprotein-based Bio-photovoltaic Devices. Mrs Proc. Spring Meet. 2013, 1572, mrss13-1572-ss06-03. [CrossRef]

12. Yaghoubi, H.; Lafalce, E.; Jun, D.; Jiang, X.; Beatty, J.T.; Takshi, A. Large Photocurrent Response and External Quantum Efficiency in Biophotoelectrochemical Cells Incorporating Reaction Center Plus Light Harvesting Complexes. Biomacromolecules 2015, 16, 1112-1118. [CrossRef] [PubMed]

13. Yehezkeli, O.; Tel-Vered, R.; Michaeli, D.; Willner, I.; Nechushtai, R. Photosynthetic reaction centerfunctionalized electrodes for photo-bioelectrochemical cells. Photosynth. Res. 2014, 120, 71-85. [CrossRef] [PubMed]

14. Malhotra, B.D. Biosensors: Fundamentals and Applications; Smithers rapra: Akron, OH, USA, 2017.

15. Sze, S.M.; Kwok, K.N. Physics of Semiconductor Devices, 3rd ed.; John Wiley \& Sons, Inc.: Hoboken, NJ, USA, 2006.

16. Vu, C.-A.; Chen, W.-Y. Field-effect transistor biosensors for biomedical applications: Recent advances and future prospects. Sensors 2019, 19, 4214. [CrossRef] [PubMed]

17. Mahmoudzadeh, A.; Saer, R.; Jun, D.; Mirvakili, S.M.; Takshi, A.; Iranpour, B.; Ouellet, E.; Lagally, E.T.; Madden, J.D.W.; Beatty, J.T. Photocurrent generation by direct electron transfer using photosynthetic reaction centres. Smart Mater. Struct. 2011, 20, 094019. [CrossRef]

18. Goldsmith, J.O.; Boxer, S.G. Rapid isolation of bacterial photosynthetic reaction centers with an engineered poly-histidine tag. Biochim. Biophys. Acta (BBA) Bioenerg. 1996, 1276, 171-175. [CrossRef]

19. Jones, M. Structural Plasticity of Reaction Centers from Purple Bacteria. In The Purple Phototrophic Bacteria; Hunter, C.N., Daldal, F., Thurnauer, M., Beatty, J.T., Eds.; Springer: Cham, The Netherlands, 2009; Volume 28, pp. 295-321.

20. Abresch, E.C.; Axelrod, H.L.A.; Beatty, J.T.; Johnson, J.A.; Nechushtai, R.; Paddock, M.L. Characterization of a Highly Purified, Fully Active, Crystallizable RC-LH1-PufX Core Complex from Rhodobacter sphaeroides. Photosynth. Res. 2005, 86, 61-70. [CrossRef] [PubMed]

Publisher's Note: MDPI stays neutral with regard to jurisdictional claims in published maps and institutional affiliations. 